\title{
Exploring gender and gender pairing in the knowledge elaboration processes of students using computer-supported collaborative learning
}

\author{
N. Ding*, R.J. Bosker, E.G. Harskamp \\ Faculty of Behavioural and Social Sciences, University of Groningen, The Netherlands
}

\section{A R T I C L E I N F O}

\section{Article history:}

Received 23 February 2010

Received in revised form

7 June 2010

Accepted 11 June 2010

\section{Keywords:}

Gender

CSCL

Knowledge elaboration

\begin{abstract}
A B S T R A C T
The aim of the study is to investigate the influence of gender and gender pairing on students' learning performances and knowledge elaboration processes in Computer-Supported Collaborative Learning (CSCL). A sample of ninety-six secondary school students, participated in a two-week experiment. Students were randomly paired and asked to solve several moderately structured problems concerning Newtonian mechanics. Students' pretest and posttest performances were analyzed to see whether students' gender and the gender pairing (mixed or single-gender) were significant factors in their problem solving learning in CSCL. Students' online interactions were also analyzed to unravel the dynamic process of individual knowledge elaboration. The multilevel analyses revealed that a divergent pattern of knowledge elaboration was a significant predictor for students' learning achievement, and in mixed-gender dyads students' knowledge elaboration processes were more inclined to diverge from each other. Moreover, females in single-gender dyads significantly outperformed females in mixed-gender dyads. But this was not the case for male students.
\end{abstract}

(ㄷ) 2010 Elsevier Ltd. All rights reserved.

\section{Introduction}

It seems to be a global problem that physics is confronted with the largest gender gap in school practice. Males tend to outscore female students in physics (Sadker \& Sadker, 1994), and females drop out of physics-related majors at a higher rate than do males (Garratt, 1986). Computer-Supported Collaborative Learning (CSCL) affords the opportunity to lessen the gender gap in this regard. It has become a promising heuristic technique in school practice, and in the past decade it has been increasingly applied as an integral part of physics education. In CSCL, students work together to achieve a joint goal such as solving a problem or writing a report. Collaboration involves individual's cognitive elaboration (Stahl, Koschmann, \& Suthers, 2006). The effectiveness of CSCL is based on two premises: a) collaborative learning can have profound effects on students' learning achievement (Johnson \& Johnson, 1993; Teasley, 1995); b) the promising potential of computers can connect isolated learners in an innovative way (Stahl et al., 2006). Although both premises have already gained sufficient empirical support, both are controversial where gender is concerned.

As for collaboration, although some researchers claim that it appeals to both male and female students (Heller \& Lin, 1992; Johnson \& Johnson, 1993; Kahle \& Meece, 1994), some studies clearly addressed a gender difference in communication styles (Guiller \& Durndell, 2006; Lakoff, 1973; Lay, 1992; Li, 2002) and a difference in gender pairing such as single and mixed-gender collaboration in terms of interaction and learning performance (Howe, Tolmie, Anderson, \& Mackenzie, 1992). With respect to computer-mediated communication, some researchers have found a gender difference in online language style (Leaper \& Smith, 2004; Stewart, Shields, Monolescu, \& Taylor, 1999), online communication style (Savicki, Kelley, \& Oesterreich, 1999) and participation pattern (Ross, 1996). According to Underwood, Underwood, and Wood (2000), collaborative learning carries risks and these risks are particularly high where computer and gender are involved. Yet, to date, little research has been done to study the influence of gender and gender pairing on students' learning in synchronous CSCL settings. There remain some essential questions that need empirical investigation, such as: Do female and male students benefit equally from mixed- and single-gender dyads in synchronous CSCL? To be explicit, it is still unclear whether the knowledge elaboration process in mixed-gender dyads presents a different picture in comparison with that in single-gender dyad, and how the relationship is moderated by the gender pairing.

\footnotetext{
* Corresponding author. Faculty of Behavioural and Social Sciences, University of Groningen, PO Box 1286, 9701 BG Groningen, The Netherlands. Fax: +31 50363 6670. E-mail address: n.ding@rug.nl (N. Ding).
} 
The aim of the current study is to investigate the influence of gender and gender pairing on knowledge elaboration and learning performance in synchronous physics problem solving settings. The research questions are formulated as follows:

- In CSCL for physics problem solving, is there a difference in knowledge elaboration processes between mixed-and single-gender dyads?

- In CSCL for physics problem solving, is there a gender difference in learning achievement?

Exploring these questions will deepen our understanding of the nature of knowledge elaboration processes in online collaboration and provide an insight into an effective instructional design for CSCL. In what follows, a review of knowledge elaboration and gender differences in communication in CSCL will be given. After that, the design of the study will be introduced. Then, we will examine the gender difference in learning performance and knowledge elaboration patterns. In the results section, we will study the relationship between students' gender, knowledge elaboration and learning performance with the help of multilevel analyses. Finally, the research implications will be discussed.

\section{Knowledge elaboration in CSCL}

Elaborating knowledge defines how students expand and refine new information through organizing, structuring, and connecting with their prior knowledge. Through knowledge elaboration students build up a new understanding of their knowledge. This is an important component of collaborative learning. Collaborative learning hinges on the idea that learners possess different unshared prior knowledge (Weinberger, Stegmann, \& Fischer, 2007). When different parts of prior knowledge are shared, combined and reconstructed, collaboration has an added value over individual learning (Pfister, 2005). In dyadic collaboration, each dyad can be viewed as a group with its own properties, but comprised of two relatively independent learners. The learners vary in their degree of contribution to the final result during collaboration. In collaborative learning, according to Roschelle and Teasley (1995), learning is enhanced when learners are engaged in a "coordinated and synchronous activity that is the result of a continued attempt to construct and maintain a shared conception of a problem" (pp.70).

Suthers (2006) distinguished two roles technology plays in CSCL: communication medium and constraint. On the one hand, students' interactions are preserved in a shared context, which may deepen students' thinking and facilitate a high level of elaboration. Moreover, learners have the opportunity to look back at the text that has been exchanged. Explicit back-references such as these afford the opportunity to trigger more thoughtful and reflective discussions. On the other hand, to date, synchronous CSCL is mainly mediated via text-based communication. The learners cannot see each other face-to-face. Such reduced shared context makes it harder for learners to comprehend the meaning of their interlocutor and become fully involved in the discussion (Suthers, 2006). The shared context represents the multiple facets that facilitate the negotiation of interpersonal questions. Moreover, due to the ease of typing and exchanging messages, synchronous CSCL may generate numerous fragmented and incoherent interactions. Interactions in synchronous CSCL are not static but are brief and incomplete (Ding, 2009; Neuage, 2002). Furthermore, Veerman and Veldhuis-Diemanse (2001) found that questions posted in synchronous CSCL tended to be easily ignored. The synchronous interactions were fleeting with short contributions and numerous turns. Weisband (1992) claimed that computer-mediated communication reduces conformity and convergence. Therefore, CSCL may work out in different ways depending on how well students can communicate and elaborate their knowledge mutually.

Koschmann et al. (2005) claim that in computer-supported collaborative learning, knowledge and meaning can be understood as jointly created through interaction which is mediated through computers. In collaborative problem solving, a dyad can be viewed as a unit made up of two interdependent cognitive units (Dillenbourg, Baker, Blaye, \& O'Malley, 1995). Hmelo-Silver (2003) points out that the prerequisite for delving into collaborative learning is to make sense of the students' conversation and the tools mediating their roles. Insight into learners' interactions is an important step towards unraveling the dynamic nature of individuals' knowledge elaboration (Arvaja, Salovaara, Hakkinen, \& Jarvela, 2007; Brown \& Palincsar, 1989). Doing so is based on the rationale that students' discourse data represent their cognitive processes of learning to a certain degree (Chi, 1997). However, there is no consensus regarding how to code students' interactions in an appropriate way (Hmelo-Silver \& Bromme, 2007). Some researchers focus on the cognitive quality of students' interactions (e.g. Gudzial \& Turns, 2000) because these interactions reflect the state of the students' knowledge. Moreover, representing information and high-level cognitive processing of information are closely intertwined in science problem solving (Kozma \& Russel, 1997; Toth, Suthers, \& Lesgold, 2002). Analyzing students' text-based and graphical representations during collaborative problem solving can deepen our understanding of students' cognitive contributions towards the solution process and their sharing of meaning (DeWindt-King \& Goldin, 2003).

Kumpulainen and Mutanen (1999) differentiated three cognitive dimensions of peer-group interaction by focusing on the nature of cognitive processing. Apart from off-task activities, they distinguished procedural processing and interpretative or exploratory processing activities of individual learners. The researchers described frequencies of these dimensions during collaborative work. Based on that, Ding (2009) endowed each message with an elaboration value: $-1,0$ or +1 , and plotted the sums of the values for each individual learner along a timeline. For dyadic collaboration, there are two individual curves that may intertwine or not. This visual analysis reveals at least three patterns of knowledge elaboration. The divergent pattern (on the left in Fig. 1), featuring two diverging curves, shows an increasing cognitive discrepancy in interactions between the two participants. The cross pattern (in the middle in Fig. 1) illustrates the fact that students' knowledge elaboration processes are closely intertwined. The participants keep a close eye on their partners' processing and take turns dominating the knowledge elaboration. The parallel pattern (on the right in Fig. 1) shows two roughly parallel curves, indicating that the cognitive gap between the two participants stayed the same during collaboration. With the help of the patterns, we were able to trace the knowledge elaboration processes of the learners and explore the gender difference in CSCL.

\section{Gender difference in CSCL}

CSCL is assumed to alleviate the gender gap due to the reduced contextual cues. In synchronous computer-mediated communication, students do not see each other and all messages are in text or in graphical representations. Warschauer (1997) suggested that three factors of CSCL contributed to closing the gender gap: 1) the reduced contextual clues masking the gender characteristics; 2) the reduced nonverbal cues such as frowning that can intimidate partners; and 3) the opportunities for students to regulate their learning processes. 


\section{divergent pattern}

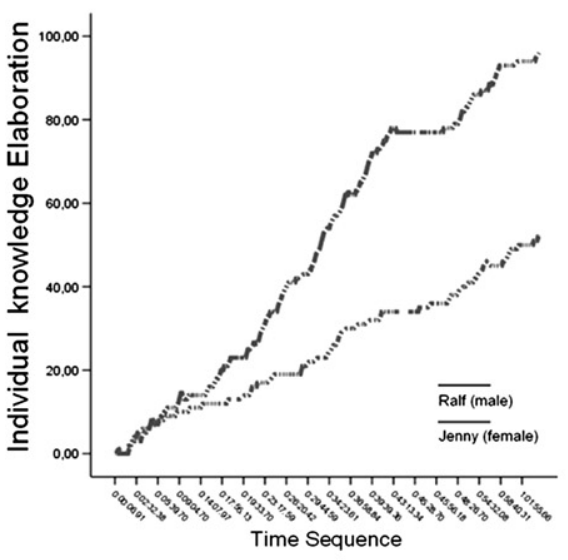

\section{cross pattern}

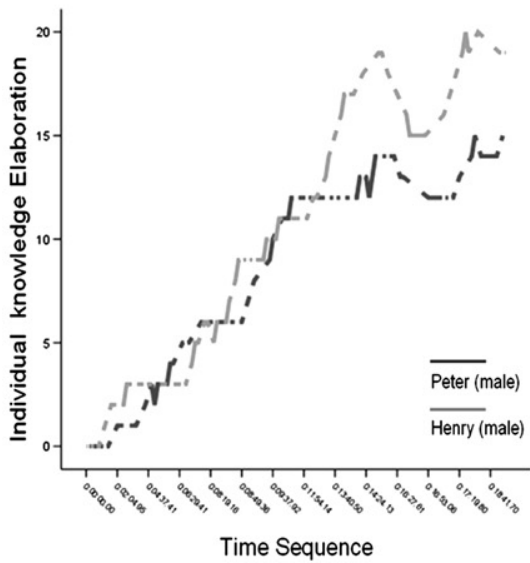

Fig. 1. Knowledge elaboration patterns (Ding, 2009).

\section{parallel pattern}

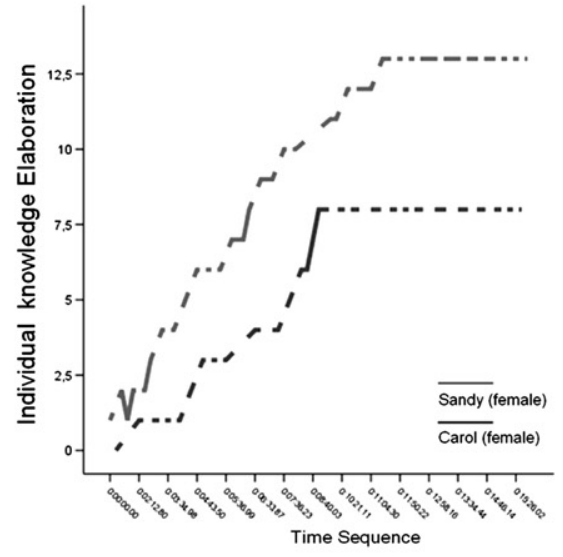

However, this is still a controversial claim, especially in a synchronous CSCL setting. Some studies have reported that ICT has a more positive effect on males by extending their interest span (Passey, Rogers, Machell, McHugh, \& Allaway, 2003). The pressure to respond in live-talk may hinder female students from developing their own problem solving strategies. The breakdown in interaction may turn out to be a potential problem in mixed-gender collaboration.

In comparison with single-gender collaboration, the interaction in mixed-gender groups is found by some researchers to be an awkward experience (Howe \& Tolmie, 1999; Howe et al., 1992). Underwood et al., (2000) found that female and male students in the mixed-gender dyads did not engage in true collaboration because they were not jointly focused on the problem. Prinsen, Volman, and Terwel (2007) have reviewed thirteen studies on the gender problem in Computer-Mediated Communication (CMC) and CSCL. They focused on three aspects: degree of participation, kind of participation, and experience of participation. The review study reveals that in mixed-gender groups males tended to dominate the discourse and had a more positive group-work experience. Inzlicht and Ben-Zeev (2000) ascribed this to the stereotype threat. They found that the mere presence of a male can weaken females' problem solving skills. Kessels and Hannover (2008) investigated around four hundred eighth-graders in German schools. Students were randomly assigned to single and mixed-gender physics classes. They found that females from single-gender physics classes outperformed females from mixed-gender classes, while male students achieved equally well in both kinds of classes.

In other studies, however, researchers could not find a significant difference between males and females' performance (Joiner, Messer, Littleton, \& Light, 1996; Underwood, Jindal, \& Underwood, 1994). Some researchers (e.g. Howe \& Tolmie, 1999; Pheasy \& Underwood, 1994) could find no empirical support for a difference in learning performance concerning gender pairing. It seems that the positive attitude of males towards computer could not be translated into a learning advantage over females (Harrison et al., 2002).

Fitzpatrick and Hardman (2000) have proposed several possible explanations for the differing results, for example, the task feature, the computer-based learning environment, the way the performance is assessed, etc.

In order to depict a clear picture of how female and male students exchange and process information cognitively, and benefit from collaborative learning, we resorted to a content analysis of the students' interactions. Based on previous findings, it was hypothesized that students' knowledge elaboration processes might be different in mixed- and single-gender dyads. Moreover, as indicated in Prinsen et al.'s (2007) review study, it was hypothesized that, although female students in single-gender dyads might outperform females in mixed-gender dyads, this would not be the case for male students, and it was not. Finally, students' knowledge elaboration processes were assumed to influence their learning performances. We hypothesized that the elaboration patterns could, to some extent, explain the differences in the learning achievement of male and female students in different gender pairings.

\section{Materials and methods}

\subsection{Participants}

The study was conducted in a secondary school in Shanghai, China. The school is one of the top ten schools in Shanghai. Ninety-six tenth graders, aged sixteen, participated in a two-week experiment. There were 49 females and 47 males. Participants came from two parallel classes taught by the same teacher. They knew each other well. During the experiment, students were randomly paired within the class. There were three groups of gender pairing: a group of mixed-gender dyads (MG, $n=25$ ), a group of female-female dyads (FF, $n=12$ ), and a group of male-male dyads (MM, $n=11$ ). Students were categorized into four conditions: females in mixed-gender dyads (F in MG, $n=25)$, males in mixed-gender dyads ( $\mathrm{M}$ in MG, $n=25$ ), females in female-female dyads ( $\mathrm{F}$ in FF, $n=24$ ), and males in male-male dyads (M in MM, $n=22$ ).

\subsection{Procedure}

In students' previous physics tests, there had been no significant difference between the two classes. All participants attended three regular physics lectures on Newton's Second Law. The participating students were then administered a 40-min pretest on Newton's Second 


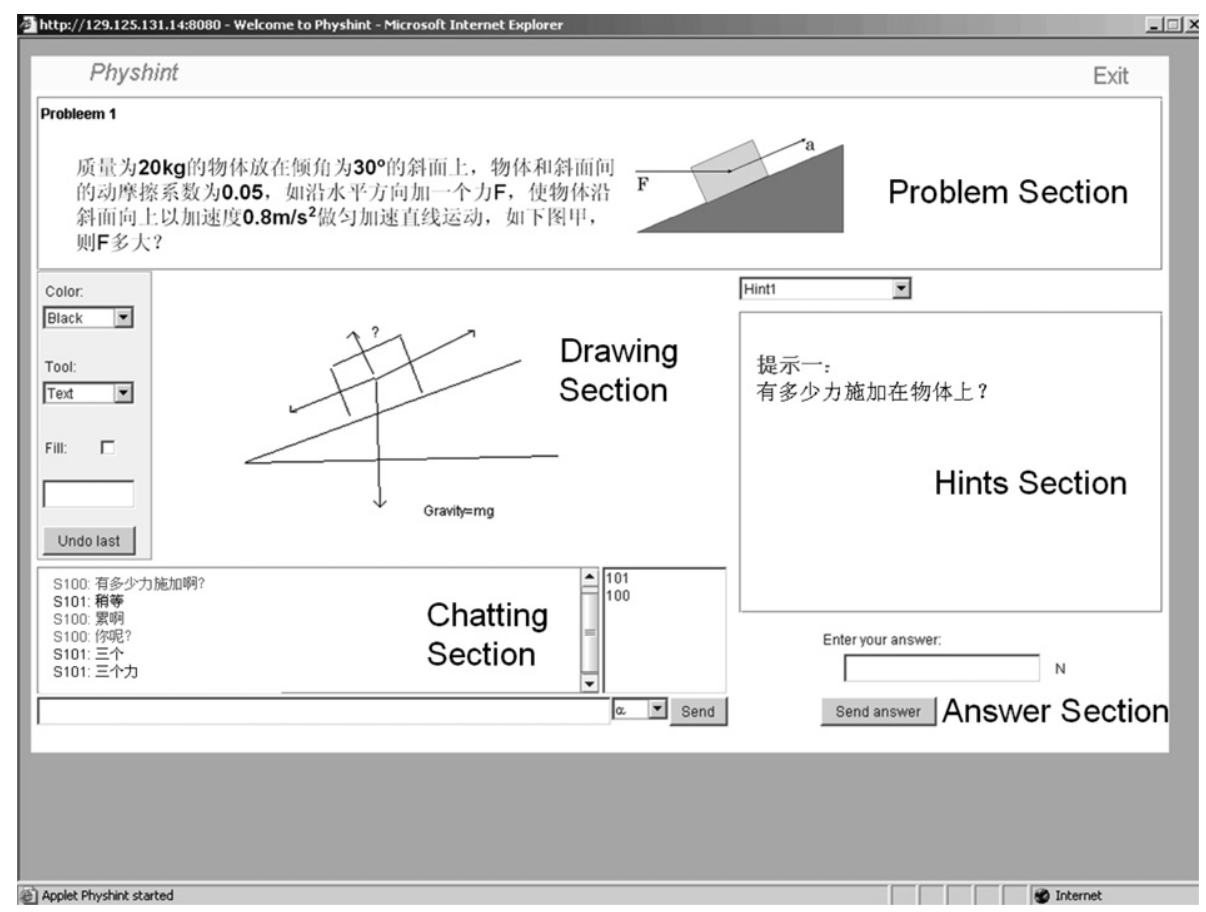

Fig. 2. Interface of PhysHint.

Law. After that, they were given a 40-min training session in how to use the online program "Physhint". The experiment lasted two weeks, including six 40-min experiment sessions. Students were asked to solve six problems in total. For each dyad, the participants were separated in different classrooms to avoid face-to-face interaction. They could only use the internet-based computer program "PhysHint" to communicate. PhysHint provides a CSCL environment through which students can use text and graphical messages to communicate. The sessions in the experiment were overseen by the local teacher and the research assistant. Students were exposed to the same number of experimental hours and the same instructional materials.

On the last day, all students participated in a 40-min posttest. This test also had four moderately structured problems, similar to the pretest. In both pretest and posttest, students were required to solve the problem independently. Both pretest and posttest were paper-andpencil tests. In each test, students were required to solve four problems about Newton's Second Law independently, without any help from peers. Students' pretest and posttest performances were scored by the local physics teacher. The full mark for both pretest and posttests was 100. Each episode in solving the problem was scored five points.

\subsection{PhysHint}

The computer program "PhysHint" was compiled in order to facilitate synchronous online collaboration. It aims at improving students' problem solving skills through text-based online collaboration. Technically, it can allow 100 dyads to work on the problems at the same time. There are five sections in the PhysHint interface, as shown in Fig. 2.

The problem section shows the problem information. The problem could not be read until both partners logged into the system. Doing this prevented one student from having more time to read and think about the problem than his/her partner (see the sample of the problem in Table 1). In this experiment, six physics problems from the database were used. Four problems (Problems 1, 2, 3, 6) had only one question, while Problems 4 and 5 included two sub-questions.

The hints section offered each student five "hints" for each problem. All the hints were compiled on the basis of Schoenfeld's (1992) five episodes of problem solving: reading the problem, recalling prior knowledge, making a plan, implementing the plan, reflecting on the answers. In order to strengthen the students' communication, we gave different hints to each student in a dyad so that they had to engage in exchanges about what they read (see the sample of hints in Table 2).

In the drawing section, students were able to draw the variables and vectors using geometric forms, arrows and lines. They could also illustrate the objects with different colors. What one student drew would be automatically shown on his/her partner's computer. The chatting section resembled the MSN Messenger or Yahoo Messenger that students were familiar with. In the texts shown we used different

Table 1

Sample problem in the PhysHint program.

I am going to push a box ( $20 \mathrm{~kg}$ ) lying on a slope so that it moves upwards with an acceleration of $0.8 \mathrm{~m} / \mathrm{s}^{2}$. I was told that the friction coefficient between the box and the slope was 0.05 , and that the angle between the slope and the ground is $30^{\circ}$. If I am going to apply a force in the horizontal direction, what is its magnitude? (The answer should be calculated to two decimals.) 
Table 2

Sample of Hints.

\begin{tabular}{|c|c|}
\hline Student A: & Student B: \\
\hline Hint 1: How many forces are being applied on the box? & Hint 1: Besides its own gravity, are there any other forces being applied on the box? \\
\hline Hint 2: How do you visualize these forces? & Hint 2: What is Newton's Second Law? \\
\hline Hint 3: The forces can be analyzed in two directions. & Hint 3: What are the directions of these forces? \\
\hline Hint 4: How do you combine the calculations in both directions? & Hint 4: The final solution is based on calculating in both directions \\
\hline Hint 5: Do you think that this is the best way to solve this problem? & Hint 5: Do you have a better solution? \\
\hline
\end{tabular}

colors (black and blue) to distinguish between the two students in the same dyad. After the students arrived at the answer, they submitted this answer using the answer section. The final submission of the answer was based on mutual agreement. For each problem each dyad had two chances to submit an answer. The second time they failed to give a correct answer, a pop-up window with a "worked-out example" was generated. Fig. 3 shows the original Chinese "worked-out example" for students and its English translation (Fig. 4).

\section{Problem $1 \quad$ Worked-Out Example}

(1) 受力分析: 物体受四个力作用: 重力 $m g$ 、弹力FN、推力F、 摩擦力Ff,

(2) 建立坐标: 以加速度方向即沿斜面向

上为X轴正向, 分解F和 $m g$ 如图乙所示;

(3) 建立方程并求解

乙

$\mathrm{x}$ 方向: $\mathrm{F} \cos a-m g \sin \alpha-\mathrm{F}_{\mathrm{f}}=\mathrm{ma}$ (1)

$y$ 方向: $F_{N}-m g \cos a-F \sin a=0$ (2)

$F_{f}=\mu F_{N}$ (3)

三式联立求解得,

$$
\frac{m(a+g \sin a+\mu g \cos a)}{\cos a-\mu \sin a}
$$

$F=[$ 答案 $]$

$$
\frac{m(a+g \sin a+\mu g \cos a)}{\cos a-\mu \sin a}
$$

$F=140.76 \mathrm{~N}$

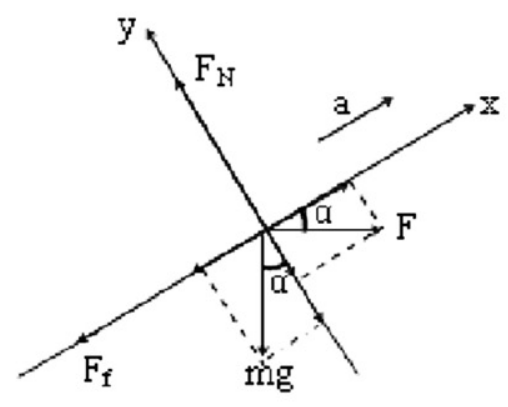

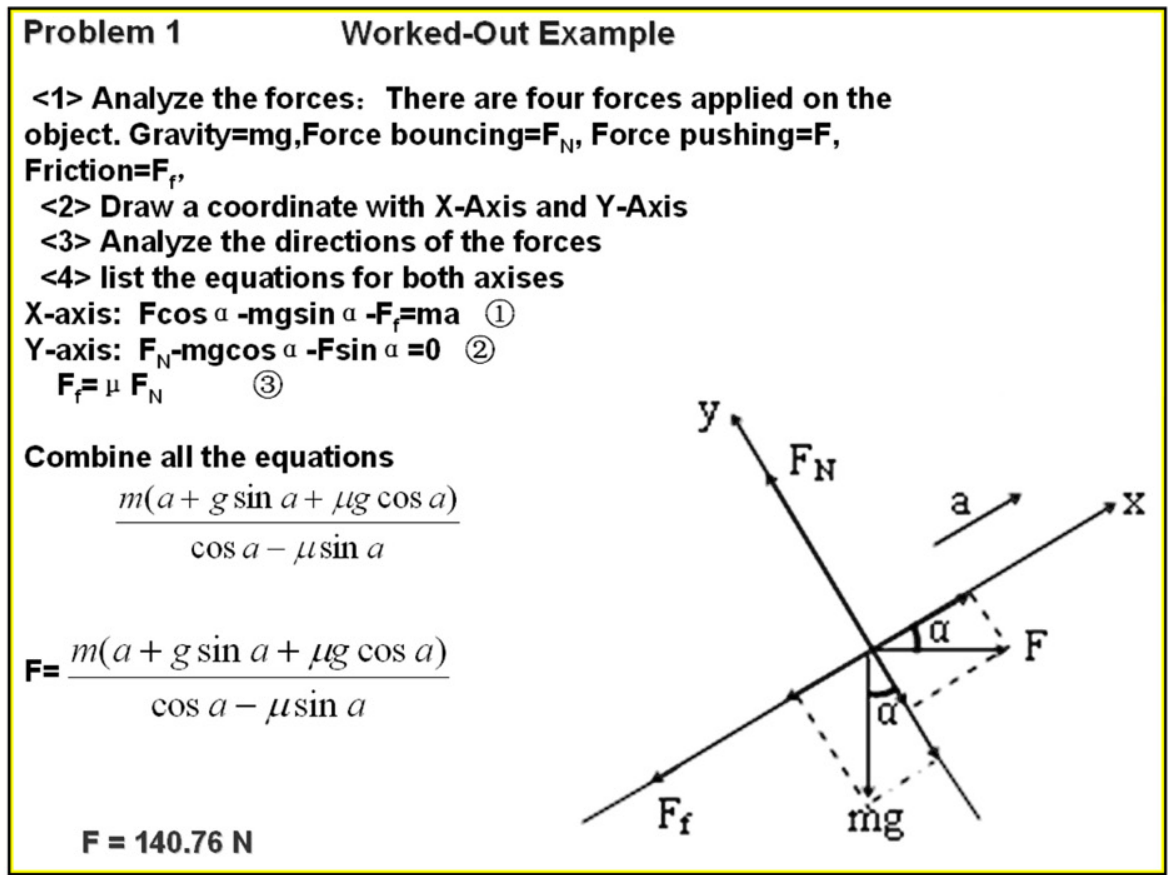

Fig. 3. Sample of worked-out example. 


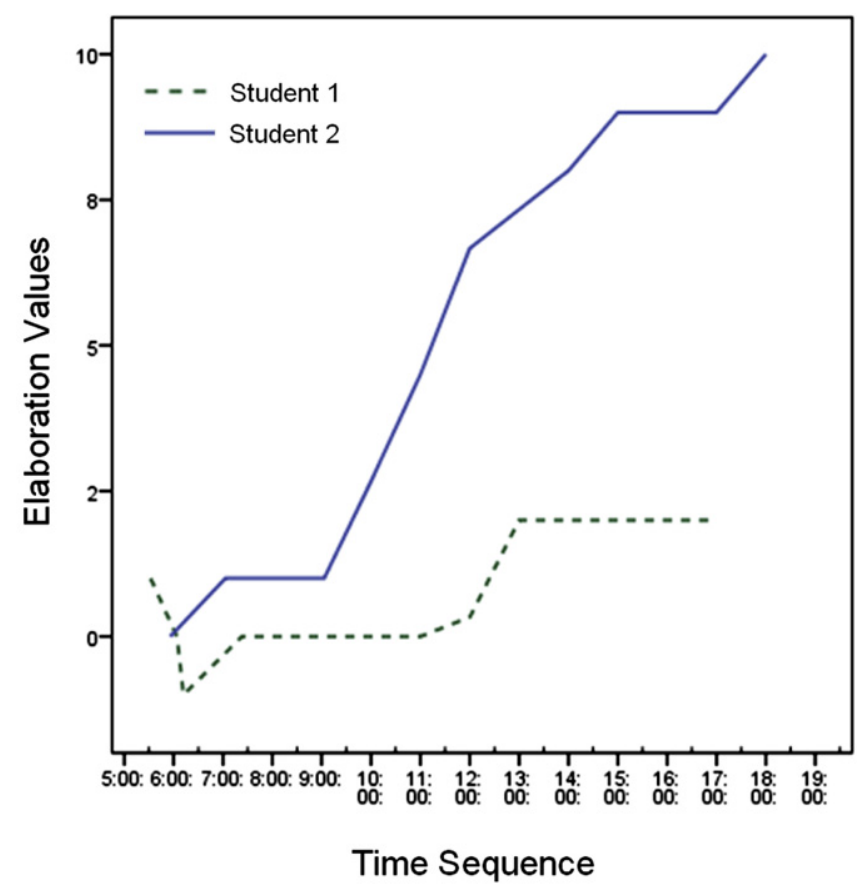

Fig. 4. Sample of divergent pattern based on the script in Table 6.

\subsection{Data Collection and analyses}

Students' online messages were collected and analyzed with "elaboration values." Table 3 shows the detailed coding system.

According to its content and contextual relationship, we quantified each message using the value $-1,0$ and +1 . If the message was offtask and distracted the students' attention while problem solving, it was scored minus one ( -1$)$. If it was a task-related message but did not improve the solving process, it was scored zero $(0)$. The presence of many 0 -valued messages indicates that students are communicating sufficiently, but that they have stopped at the surface level. This serves to distinguish between the superficial and the elaborative talk in the collaboration. When a message was pertinent to the task and was contributive to the final success in problem solving, it was scored with a one $(+1)$. It has been shown that discourse beyond the concrete level of the problem space may foster the individual acquisition of knowledge in learning scenarios based on complex problems (Hogan, Nastasi, \& Pressley, 2000).

Based on the rationale that individual contributions as data points are interdependent and can be interpreted additively, we plotted the cumulative scores of the elaboration values along the timeline and ended up with three clearly different patterns: divergent, cross and parallel.

There are three points that should be noted at this juncture. First, we have acknowledged the importance of elaborative questions. Our previous findings have indicated that female and male students have different communication styles. In collaborative problem solving, female students tend to use questions to begin the discussion or express their own ideas. An elaborative question not only kept the collaboration on the right track, but also fostered the partner's knowledge elaboration. Therefore, not only would interpretative or exploratory processing be given a +1 point, but also the elaborative question. Second, CSCL is characterized by a large amount of incoherencies in interactions, sometimes even "messy" talk. When we evaluated each individual message, we did not merely relate it to the previous messages but to the whole context. Third, when defining students' elaboration patterns, we focused on the major part of the problem solving time, and on the major feature that characterized the dyadic communication. For instance, whether the curves became entangled with each other initially or remained parallel, we noted this simply as a divergent pattern because the dominant feature was two curves diverging from each other. Apart from the aforementioned patterns, there were some patterns that the coders found difficult to categorize. For example, only half of the time did the curves become crossed; for the rest of the time, they remained parallel. Such patterns were categorized as "ambiguous patterns."

Table 3

Elaboration Values.

\begin{tabular}{|c|c|c|}
\hline Number & Description & Example \\
\hline+1 & on-task message elaborating on knowledge or contributing to the final solution. & $\begin{array}{l}\text { Student A: How many forces are applied on the box? } \\
\text { Student B: I think, four }\end{array}$ \\
\hline 0 & $\begin{array}{l}\text { on-task message but no improvement in knowledge elaboration or } \\
\text { problem solving }\end{array}$ & $\begin{array}{l}\text { (Student B: There are four forces being applied on the box.) } \\
\text { Student A: OK. }\end{array}$ \\
\hline-1 & off-task messages distracting the problem solving process & Student B: What's your guess about what will be in our next English test? \\
\hline
\end{tabular}


Table 4

Mean numbers and standard deviations of text-based and pictorial messages per student for all six problems.

\begin{tabular}{|c|c|c|c|c|}
\hline Factors & Female & & Male & \\
\hline \multirow[t]{2}{*}{ Mixed-Gender } & Text-based Messages & Pictorial Messages & Text-based Messages & Pictorial Messages \\
\hline & $458.76(113.03)$ & $3.04(1.67)$ & $434.84(151.43)$ & $4.68(1.70)$ \\
\hline \multirow[t]{2}{*}{ Single-Gender } & Text-based Messages & Pictorial Messages & Text-based Messages & Pictorial Messages \\
\hline & 509.25(127.67) & $5.00(1.96)$ & 513.64(167.61) & $7.32(2.12)$ \\
\hline
\end{tabular}

\section{Results}

\subsection{Implementation of the study}

Due to strict school rules, no student dropped out during the experiment. For all the students in the experiment, there had been no significant gender difference in any of their previous regular physics tests.

In condition MG, female and male students were randomly paired to solve the problems in a CSCL setting. It is interesting to note that when the female students knew that they were to be paired with a male student, two female students raised their hands and asked to be allowed to work with a female student. But nothing similar occurred in the condition FF and MM. The ANOVA test with "pretest" as the dependent variable, and "group" and "gender" as the independent factors shows that there was a significant difference between male and female students in their pretest scores $\left(F_{(1,92)}=5.49, p=.01\right)$, though the difference was not significant for the group pairing $\left(F_{(1,92)}=0.01\right)$, nor for the interaction between gender and gender pairing, $\left(F_{(1,92)}=2.03\right)$.

The study was based on a quantitative analysis of the students' learning achievement and a content analysis of the students' online interaction. In the experiment, all online interactions were documented automatically by the server computer. These included their visual and verbal messages. During the six experiment sessions, students produced 45862 text-based messages; 474 were pictorial messages. Tables 4 and 5 summarize the mean numbers and standard deviations for all messages, on-task, off-task, text-based and pictorial messages for all six problems per student. It is notable that there was a significant gender difference in terms of pictorial messages $\left(F_{(3,92)}=18.47\right.$, $p=.02$ ). Male students generated significantly more pictorial messages during problem solving than female students. This echoes our previous findings about a gender difference in terms of ways of representing knowledge in physics problem solving (Ding \& Harskamp, 2010). For the other categories, there was no significant difference.

\subsection{Knowledge elaboration}

Analyzing students' interaction content is one of the challenges in CSCL research (Lipponen, Rahikainen, Lallimo, \& Hakkarainen, 2003) because CSCL is characterized by its dynamically evolving context of interaction (Hmelo-Silver \& Bromme, 2007).

Five Chinese sophomores majoring in mechanical engineering were trained as independent coders. They were very knowledgeable about Newtonian mechanics. They were instructed on how to evaluate each message from a knowledge elaboration perspective, as well as how to avoid treating each message in an isolated way, and how to code using the "Elaboration Value" system. After quantifying each message, they went on to visualize the knowledge elaboration process for each individual student by plotting the cumulative scores of "elaboration values" sequentially. We selected the data from all six problems. Due to the huge amount of data, each coder spent more than $20 \mathrm{~h}$ on coding. The inter-rater reliability calculated by a Pearson product-moment correlation was 0.74 . Table 6 is an extract of one dyad's CSCL script based on the problem shown in Table 1. Fig. 6 shows the divergent pattern based on their cumulative scoring of elaboration values.

Table 7 shows the total number of knowledge elaboration patterns for each gender pairing (MG, FF, MM). For all six problems, the whole mixed-gender group produced 31 cross patterns, 37 parallel, and 78 divergent patterns. The proportion of divergent patterns was $52 \%$. This indicates that for half of the problem solving activities, students in the mixed-gender dyads were involved in divergent patterns.

For the cross patterns, the difference between the single and mixed-gender groups was not significant, $F_{(2,95)}=1.85$. Neither was the difference for parallel patterns significant, $F_{(2,95)}=2.23$. But when it came to divergent patterns, the group of mixed-gender dyads generated significantly more divergent patterns than the other two groups, $F_{(2,95)}=3.40, p=.04$.

\subsection{Learning performance and knowledge elaborations}

The second research question concerns students' learning achievement in CSCL, specifically, whether students' learning achievement is sensitive to their partner's gender.

The analysis of covariance (ANCOVA) of the students' posttest performance, using their pretest scores as the covariate and their conditions as predictor, shows that the effect of the pretest was significant $\left(F_{(1,88)}=588.53, p=.00\right)$.

We performed multilevel analyses, with the posttest scores as dependent variable. The adoption of multilevel analyses is based on the acknowledgement that students within a dyad share something in common (the observations are dependent rather than independent).

Table 5

Mean numbers and standard deviations of on-task and off-task messages per student for all six problems.

\begin{tabular}{|c|c|c|c|c|}
\hline Factors & Female & & Male & \\
\hline \multirow[t]{2}{*}{ Mixed-Gender } & On-task Messages & Off-task Messages & On-task Messages & Off-task Messages \\
\hline & $231.04(69.97)$ & $230.76(100.46)$ & $363.24(123.39)$ & $76.28(216.63)$ \\
\hline \multirow[t]{2}{*}{ Single-Gender } & On-task Messages & Off-task Messages & On-task Messages & Off-task Messages \\
\hline & $337.50(101.84)$ & $176.75(114.39)$ & $329.82(99.84)$ & 191.14(172.97) \\
\hline
\end{tabular}


Table 6

Extract of a mixed-gender dyad's CSCL script based on the problem in Table 1.

\begin{tabular}{|c|c|c|c|c|}
\hline Line & Time & Gender & Transcripts & Elaboration Values \\
\hline 1 & $05: 32$ & Student 1 & How many forces? & 1 \\
\hline 2 & 05:56 & Student 2 & wait & 0 \\
\hline 3 & 06:04 & Student 1 & I feel tired & -1 \\
\hline 4 & $06: 12$ & Student 1 & $\& \mathrm{u} ?$ & -1 \\
\hline 5 & 07:03 & Student 2 & three & 1 \\
\hline 6 & 07:06 & Student 2 & forces & 0 \\
\hline 7 & $07: 23$ & Student 1 & gravity, pushing, friction? & 1 \\
\hline 8 & $07: 58$ & Student 2 & yep & 0 \\
\hline 9 & $08: 46$ & Student 1 & r u sure? & 0 \\
\hline 10 & 09:03 & Student 2 & wait, draw $4 \mathrm{u}$ & 0 \\
\hline 11 & 09:05 & Student 1 & ok & 0 \\
\hline 12 & $10: 12$ & Student 2 & & 1 \\
\hline 13 & $10: 15$ & Student 1 & and & 0 \\
\hline 14 & $10: 27$ & Student 2 & then, construct a coordinate & 1 \\
\hline 15 & $10: 35$ & Student 1 & and & 0 \\
\hline 16 & $10: 46$ & Student 1 & but, in which direction? & 0 \\
\hline 17 & $10: 52$ & Student 2 & like this & 0 \\
\hline 18 & $11: 26$ & Student 2 & & 1 \\
\hline 19 & $11: 53$ & Student 2 & $G=196$ & 1 \\
\hline 20 & $11: 55$ & Student 1 & $?$ & 0 \\
\hline 21 & $12: 01$ & Student 2 & & 1 \\
\hline 22 & $12: 06$ & Student 1 & ok & 0 \\
\hline 23 & $12: 09$ & Student 2 & then, go to $\mathrm{f}$ & 1 \\
\hline 24 & $12: 16$ & Student 1 & Wait wait & 0 \\
\hline 25 & $12: 32$ & Student 2 & $?$ & 0 \\
\hline 26 & $12: 59$ & Student 1 & Is it finished? I think... & 1 \\
\hline 27 & $13: 25$ & Student 1 & & 1 \\
\hline 28 & $14: 18$ & Student 2 & $\mathrm{O}$, yeah, the bouncing force & 0 \\
\hline 29 & $14: 26$ & Student 2 & $\mathrm{X}$-axis & 1 \\
\hline 30 & $14: 39$ & Student 2 & $F^{*} \operatorname{Cos} 30-196^{*} \operatorname{Sin} 30-u m g \operatorname{Cos} 30$ & 1 \\
\hline 31 & $15: 07$ & Student 2 & Y axis $->G^{*} \operatorname{Cos} 30+F_{-}$push ${ }^{*} \operatorname{Sin} 30$ & 0 \\
\hline 32 & $16: 11$ & Student 1 & !! 2 fast & 0 \\
\hline 33 & $17: 25$ & Student 2 & answer $=136.48$ & 0 \\
\hline 34 & $17: 36$ & Student 1 & sure? & 0 \\
\hline 35 & $18: 04$ & Student 2 & & 1 \\
\hline 36 & $18: 06$ & Student 2 & submitted the & of the female \\
\hline
\end{tabular}


Table 7

Sum of students' knowledge elaboration patterns for all six problems.

\begin{tabular}{|c|c|c|c|c|c|}
\hline & Cross Patterns & Parallel Patterns & Divergent Patterns & Ambiguous & Total \\
\hline Mixed-gender dyads (dyad $n=25$ ) & $30(20.67 \%)$ & $37(24.67 \%)$ & $78(52.00 \%)$ & $4(2.67 \%)$ & 150 \\
\hline Female-female dyads (dyad $n=12$ ) & $15(29.17 \%)$ & $17(40.28 \%)$ & 38 (26.39\%) & $2(4.17 \%)$ & 72 \\
\hline Male-male dyads $($ dyad $n=11)$ & $14(22.72 \%)$ & $17(40.90 \%)$ & $33(28.79 \%)$ & $5(7.58 \%)$ & 66 \\
\hline
\end{tabular}

CSCL research should take the interdependency of individuals and their learning processes into consideration (Cress, 2008). Moreover, we can carefully assess the effect of dyad properties (especially gender pairing) alongside individual student characteristics, and at the same time do justice to the fact that the number of dyads involved is only half of the number of students involved, which has implications for the correct estimation of standard errors. And, finally, cross-level interaction effects (between dyad characteristics and student characteristics) can be explored in this way (De Wever, van Keer, Shellens, \& Valcke, 2007; Snijders \& Bosker, 1999).

The dependent variable in the multilevel analyses was the students' posttest scores, with gender (Level 1) hierarchically nested within the gender pairing (Level 2) and elaboration patterns (Level 2). Table 8 presents the results of the multilevel analyses with an estimation for individual posttest scores.

We first established an empty model without any independent variables (Snijders \& Bosker, 1999). The intra-class correlation is 127.92/ $(127.90+66.88)$, or 0.66 , which means that $66 \%$ of the total variance in students' posttest scores is accounted for by the dyadic level. In other words, the dyads differ substantially more in their average posttest scores than do the students with their individual posttest scores within the dyads.

We then added explanatory variables to the model step by step. In Model 1, the coefficient is students' pretest scores. The reduction in deviance showed students' pretest achievement to be a significant predictor for their posttest performance $\left(\chi^{2}(95)=182.39, p=.00\right)$. Moreover, given the pretest differences, the dyads no longer differed significantly in their true posttest averages.

In Models 2 and 3, students' gender and group gender were introduced as predictors, respectively. In Model 2, the males were the reference group, and in Model 3 the single-gender dyads were the reference group. The reduction in deviance suggested that very few of the differences between students was explained by their gender $\left(\chi^{2}(1)=1.97\right)$ or group $\left(\chi^{2}(2)=2.61\right)$. In short, there were no significant gender and gender-pairing effects. Taking students' pretest scores into account, female students were found to achieve equally as well as male students on the posttest. In addition, students in the mixed-gender dyads performed almost the same as those in the single-gender dyads.

We then focused on the interaction of gender and group in Model 4. The reference group was female students in the mixed-gender dyads. The analysis showed that the interaction effect for gender pairing and gender was significant and that this model fitted the data better than the previous models $\left(\chi^{2}(3)=10.27\right)$. With respect to our second research question then, this result would indicate that females in mixedgender dyads performed significantly worse than other students and more specifically, worse than females in single-gender dyads.

\subsection{Interaction between knowledge elaboration pattern and gender}

As mentioned previously, there were significantly more divergent patterns in the mixed-gender dyads than in the single-gender dyads. Still, analyses of individual learning performance and counting the frequency of the patterns alone seemed inadequate when it came to explaining whether the frequency of divergent patterns correlated with students' learning performance. Therefore, with the hierarchical structure of the data in mind, we continued with multilevel analyses to answer the third research question.

We constructed Model 5, adding the number of divergent patterns as predictor, to examine whether the relatively low performance of females in the mixed-gender dyads was related to different knowledge elaboration patterns. The reduction in deviance was significant $\left(\chi^{2}(2)=3.86, p=.049\right)$. This would indicate that the effect of the number of divergent patterns was significant $(t=1.98, p=.049)$. Most notably, however, is the fact that this does not explain why females in mixed-gender dyads do relatively worse; this effect remains significant.

We explored the interaction effect of gender and the number of divergent patterns (Model 6), and of group gender and the number of divergent patterns (Model 7). The reduction of deviance for Model 6 was not significant $\left(\chi^{2}(1)=3.50, p=.06\right)$, nor was it significant for

Table 8

Summary of the model estimates for the two-level analyses of students' posttest scores.

\begin{tabular}{|c|c|c|c|c|c|c|c|c|c|}
\hline \multirow[t]{2}{*}{ Parameter } & \multicolumn{9}{|l|}{ Model } \\
\hline & 0 & 1 & 2 & 3 & 4 & 5 & 6 & 7 & 8 \\
\hline \multicolumn{10}{|l|}{ Fixed } \\
\hline Intercept & $72.65(1.83)$ & $8.10(2.40)$ & $8.03(2.37)$ & $8.80(2.39)$ & $8.24(2.27)$ & 17.80 (3.99) & $17.36(4.14)$ & $17.31(4.15)$ & $20.01(4.65)$ \\
\hline Pretest & & $0.95(0.03)$ & $0.96(0.04)$ & $0.96(0.04)$ & $0.94(0.03)$ & $0.87(0.05)$ & $0.86(0.05)$ & $0.87(0.05)$ & $0.85(0.05)$ \\
\hline Gender & & & $-1.37(0.97)$ & $-1.41(0.96)$ & $1.77(1.33)$ & $2.38(1.34)$ & $-0.38(1.96)$ & $-0.44(1.98)$ & $-3.10(2.90)$ \\
\hline Groups & & & & $-1.52(0.94)$ & $1.50(1.28)$ & $2.41(1.33)$ & $2.95(1.34)$ & $2.45(2.45)$ & $0.31(2.97)$ \\
\hline Female in MG vs. others & & & & & $-5.90(1.79)$ & $-6.34(1.77)$ & $-7.29(1.81)$ & $-7.25(1.82)$ & $-2.87(3.95)$ \\
\hline Divergent & & & & & & $-0.93(0.47)$ & $-1.65(0.60)$ & $-1.73(0.70)$ & $-2.45(0.90)$ \\
\hline Gender * Divergent & & & & & & & $1.20(0.64)$ & $1.20(0.64)$ & $2.37(1.13)$ \\
\hline Groups * Divergent & & & & & & & & $0.17(0.71)$ & $1.03(0.99)$ \\
\hline Female * Groups * Divergent & & & & & & & & & $-1.71(1.37)$ \\
\hline Group Level & $127.90(33.63)$ & $0.00(0.00)$ & $0.00(0.00)$ & $0.00(0.00)$ & $0.00(0.00)$ & $0.00(0.00)$ & $0.00(0.00)$ & $0.00(0.00)$ & $0.00(0.00)$ \\
\hline Individual Level & $66.88(13.65)$ & $21.97(3.17)$ & $21.53(3.11)$ & $20.95(3.02)$ & $18.83(2.72)$ & $18.08(2.61)$ & $17.44(2.52)$ & $17.43(2.52)$ & $17.15(2.48)$ \\
\hline Deviance (-2 Logliklihood) & 751.45 & 569.06 & 567.09 & 564.48 & 554.21 & 550.36 & 546.86 & 546.80 & 545.25 \\
\hline Decrease in Deviance & & $182.39^{*}$ & 1.97 & 2.61 & $10.27^{*}$ & $3.86^{*}$ & 3.50 & 0.06 & 1.55 \\
\hline
\end{tabular}


Model $7\left(\chi^{2}(2)=.06\right)$. As for the question of whether the divergent patterns were correlated with the females' learning achievement in mixed-gender dyads, we constructed Model 8. In this model, we looked into the interaction effect of students' gender, group gender and the number of divergent patterns. The results showed a reduction in deviance in comparison with Model 7, but this was not significant $\left(\chi^{2}(1)=1.55\right)$. There was no significant interaction effect for gender, gender pairing and the frequency of divergent patterns on the posttest scores.

\section{Conclusion and discussion}

The aim of this study was twofold. First, it focused on the gender difference in learning performance and explored whether the single and mixed-gender dyads presented different pictures of knowledge elaboration in CSCL. Second, it investigated whether students' gender, gender pairing, and knowledge elaboration processes had an effect on students' learning achievement. From previous literature and empirical studies, we assumed that males' learning was not influenced by computer-supported collaboration. But the results presented a different picture.

In the mixed-gender dyads, our study indicated a proportionally much higher frequency of divergent patterns than cross or parallel patterns. It seems that in mixed-gender dyads, students' knowledge elaboration processes are more inclined to diverge from each other.

We also found that females in single-gender dyads significantly outperformed females in mixed-gender dyads in the posttest. For males, either this or a reverse pattern did not occur. Males in mixed-gender dyads did as well as males in single-gender dyads. The results of this study show that in a synchronous and text-based CSCL environment, females seem to profit more from single-gender collaboration than from mixed-gender collaboration. This result indicates that the gender problem that we were familiar within face-to-face collaborative learning appears to carry over into the CSCL setting.

With respect to the question of whether students' learning performance is related to their knowledge elaboration patterns, we resorted to a multilevel analysis. The analyses showed that the divergent pattern was a significant predictor for the posttest scores, but the disadvantages of females in mixed-gender dyads remained. That notwithstanding, we found that the $p$ value was .06 , which indicates that the interaction effect between gender pairing and divergent patterns is worth deeper investigation.

As Underwood and Underwood (1999) claimed, learning is at its best when the learners talk constructively together, and introduce and elaborate knowledge mutually. We used the "elaboration values" to visualize the students' knowledge elaboration processes. The divergent patterns indicate that there is a gap in the students' communication. Unlike the crossed patterns, in divergent patterns one student plays a dominant role while the interlocutor lags behind in knowledge elaboration. In addition, unlike in the parallel patterns, in the divergent patterns the gap between the two participating students grew larger and larger.

One explanation for the high frequency of divergent patterns in the mixed-gender dyads may be found in the use of pictorial messages. As mentioned above, male students produced significantly more pictorial messages than female students did. In physics problem solving, graphical representation does not merely refer to "drawing a picture.” It is recognized as a powerful step (Kohl \& Finkelstein, 2006). Problem information needs to be accurately and pictorially reflected, while problem components need to be interrelated and categorized into an abstract representation. Examples of this are found in clarifying the direction or magnitude of a force pictorially, or using a triangular diagram to analyze related forces. For many of the geometric concepts in physics problems, graphical representation can express a myriad of words in one economical form. In our study, it was found that males preferred illustrating the variables, drawing the relationships and mapping the solutions. In contrast, their female counterparts tended to use text-based messages to convey their ideas. The different ways of representation ways in physics problem solving may result in an elaboration gap.

An additional explanation for the frequent divergent patterns might be the communication styles. In physics collaborative problem solving, female and male students have different communication styles (Ding \& Harskamp, 2006). Females tend to use questions to open or elicit the discussion. In previous CSCL research, females were also found to raise more questions than males (Prinsen, Volman, Terwel, \& Van den Eeden, 2009). However, in synchronous text-based CSCL, due to the lack of social cues, the questions are fleeting and often easily ignored. Our previous case studies suggested that the ignorance of each other's questions was one of the mechanisms that led to divergent patterns (Ding, 2009). In future studies, it would be worth investigating whether ignorance of questions correlates with divergent patterns and the disadvantage of females in mixed-gender dyads.

In CSCL research, gender studies have been relegated to a lower research priority for many years (Bruckman, 2000). In an attempt to remedy this, the current study explored the interaction effect of gender, gender pairing and collaboration patterns in a synchronous textbased CSCL setting. We did not find any significant interaction effect, however. One possible explanation might be the relatively short period of CSCL treatment. In total, students were involved in six CSCL sessions and none of them had ever used CSCL in formal problem solving learning before. For future study, a broad research agenda should be required to explore the different mechanisms that may cause female students to lag behind in mixed-gender collaboration. The answer might be found in the different patterns of interaction, and the difference in use of verbal versus graphical representation and/or the communication style of the students. This might help us find a solution to closing the achievement gaps among students. Moreover, as Henderson and Dancy (2004) claimed, the best evidence of problem solving skills (as well as an understanding of problem principles) is a student's ability to solve novel problems in real life. Therefore, a delayed posttest would appear to be crucial if we are really interested in the sustained problem solving skills of the learners.

\section{References}

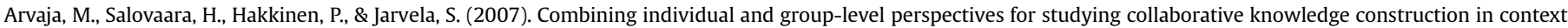
Learning \& Instruction, 17(4), 448-459.

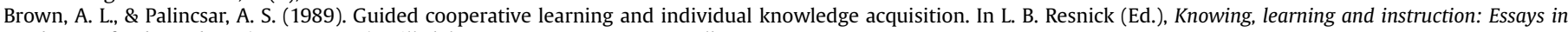
honor of Robert Glaser (pp. 395-451). Hillsdale, New Jersey: Lawrence Erlbaum.

Bruckman, A. (2000). Situated support for learning: Storm's Weekend with Rachael. Journal of the Learning Sciences, 9(3), 329-372.

Chi, M. T. H. (1997). Quantifying qualitative analyses of verbal data: a practical guide. Journal of the Learning Sciences, 6, $271-315$.

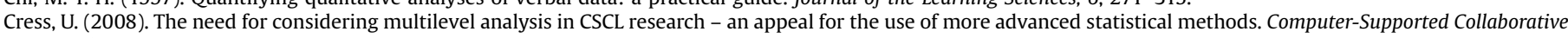
Learning, 3, 69-84. 


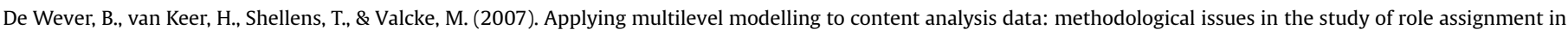
asynchronous discussion groups. Learning and Instruction, 17, 436-447.

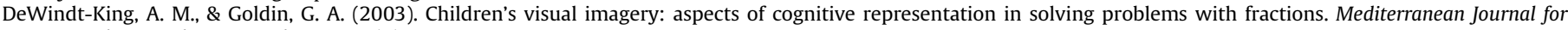
Research in Mathematics Education, 2(1), 1-42.

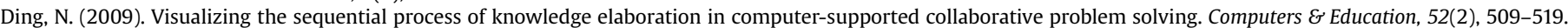

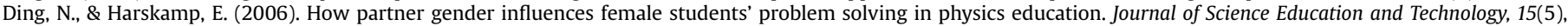
331-343.

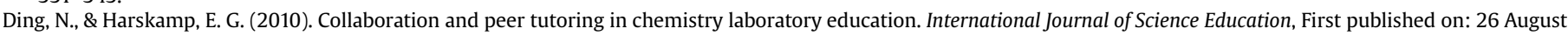
2010.

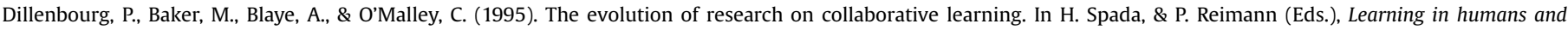
machines. Towards an interdisciplinary learning science (pp. 189-211). Oxford: Pergamon.

Fitzpatrick, H., \& Hardman, M. (2000). Mediated activity in the primary classroom: girls, boys and computers. Learning and Instruction, 10, 231-446.

Garratt, L. (1986). Gender differences in relation to science choice at A-level. Educational Review, 38(1), 67-77.

Gudzial, M., \& Turns, J. (2000). Effective discussion through a computer-mediated anchored forum. The Journal of Learning Science, 9(4), 437-469.

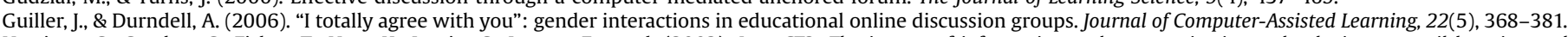

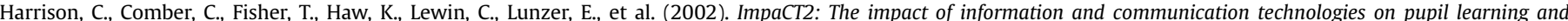
attainment. A report to the DfES. In ICT in schools research and Evaluation Series, No.7. Coventry: Becta. www.becta.org.uk/research (Online May, 2010). Retrieved from.

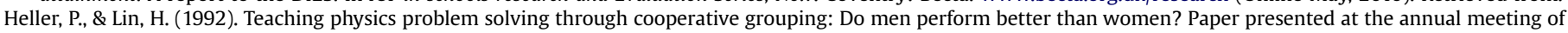
the National Association for Research in Science Teaching, Boston, MA.

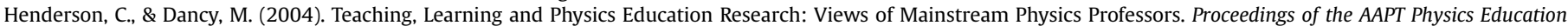
Research Conference. Sacramento, CA.

Hmelo-Silver, C. E. (2003). Analyzing collaborative knowledge construction: multiple methods for integrated understanding. Computers $\&$ Education, 41, 397-420.

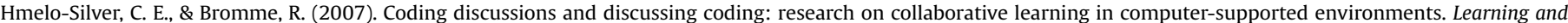
Instruction, 17, 460-464.

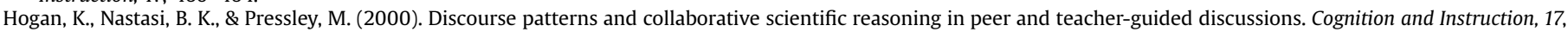
379-432.

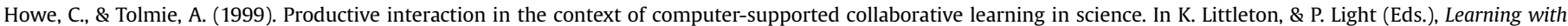
computers: Analysing productive interaction (pp. 24-45). London: Routledge.

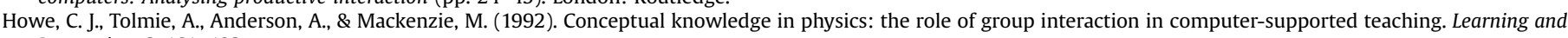
Instruction, 2, 161-183.

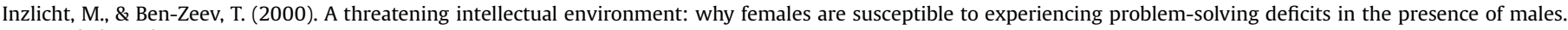
Psychological Science, 11, 365-371.

Johnson, D. W., \& Johnson, R. T. (1993). What we know about cooperative learning at the college level. Cooperative Learning, 3(3), 17-18.

Joiner, R., Messer, D., Littleton, K., \& Light, P. (1996). Gender, computer experience and computer-based problem solving. Computers E Education, 26(1-3), 179-187.

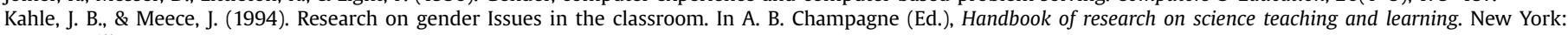
MacMillan.

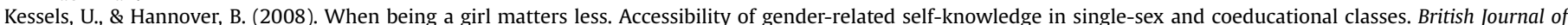
Educational Psychology, 78(2), 273-289.

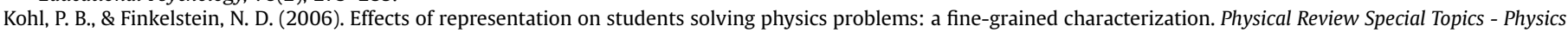
Education Research, 2. 010106.

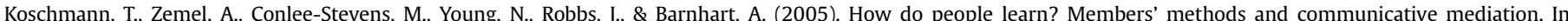
R. Bromme, F. W. Hesse, \& H. Spada (Eds.), Barriers and biases in computer-mediated knowledge communication - and how they may be overcome (pp. 265-294). NY: Springer.

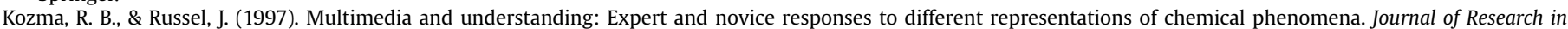
Science Teaching, 34(9), 949-968.

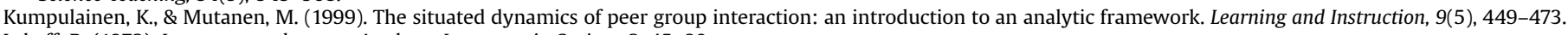

Lakoff, R. (1973). Language and woman's place. Language in Society, 2, 45-80.

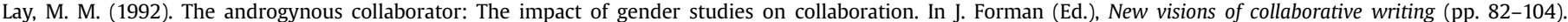
Portsmouth, NH: Boynton/Cook.

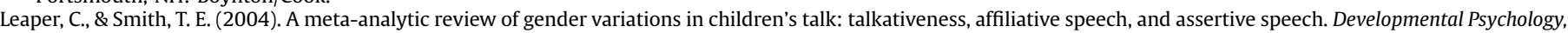
$40,993-1027$.

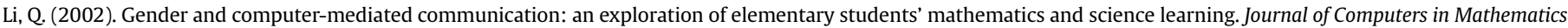
and Science Teaching, 21(4), 341-359.

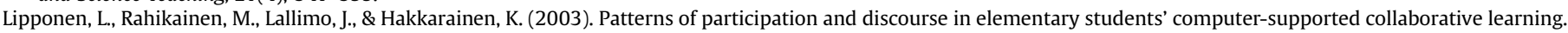
Learning and Instruction, 13(5), 487-509.

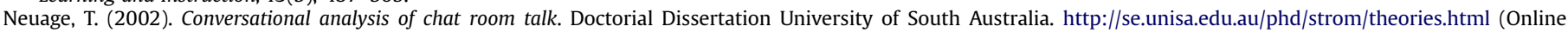
September 2003). Retrieved from.

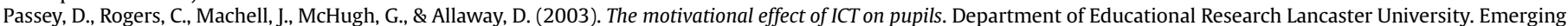
Findings, December 2003.

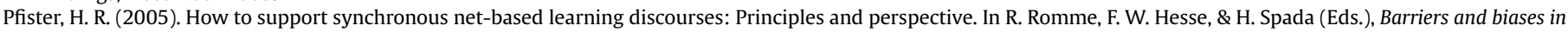
computer-mediated knowledge communication: And how they may be overcome. New York, NY: Springer.

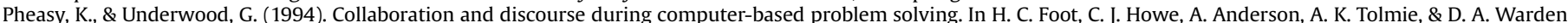
(Eds.), Group and interactive learning (pp. 105-130). Southampton: Computational Mechanics Publications.

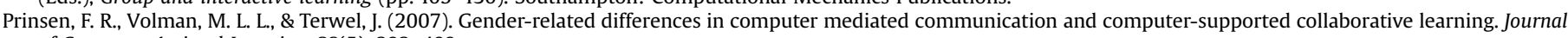
of Computer Assisted Learning, 23(5), 393-409.

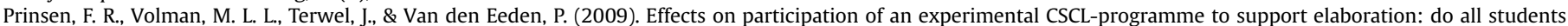
benefit? Computers E' Education, 52, 113-125.

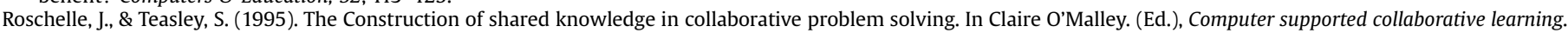
Berlin: Springer-Verlag.

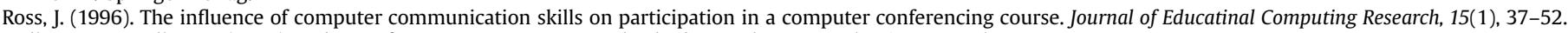

Sadker, M., \& Sadker, D. (1994). Failing at fairness: How America's schools cheat girls. New York: Simon \& Schuster.

Savicki, V., Kelley, M., \& Oesterreich, E. (1999). Judgments of gender in computer mediated communication. Computers in Human Behavior., 15, 1-10.

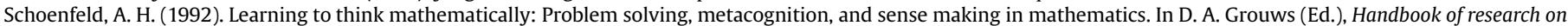
mathematics teaching and learning (pp. 334-367). NY: Macmillan.

Snijders, T. A. B., \& Bosker, R. J. (1999). Multilevel analysis: An introduction to basic and advanced multilevel modeling. London: Sage Publications.

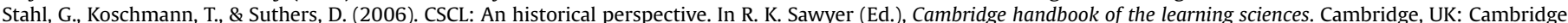
University Press.

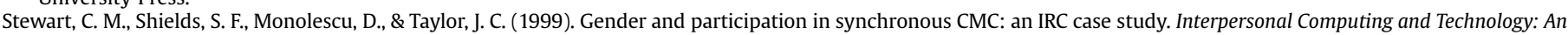
Electronic Journal for the 21st Century, 7.

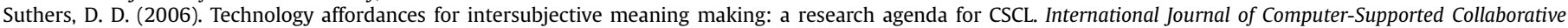
Learning, 1(3), 315-337.

Teasley, S. (1995). The role of talk in children's peer collaboration. Developmental Psychology, 3(2), 207-220.

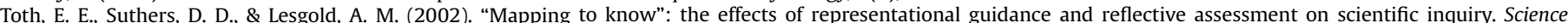
Education, 86(2), 264-286.

Underwood, G., Jindal, N., \& Underwood, J. (1994). Gender differences and effects of co-operation in a computer-based language task. Educational Research, 36, 63-74. 


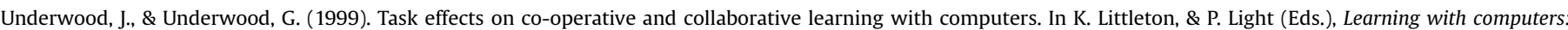
Analysing productive interaction (pp. 10-23). London: Routledge.

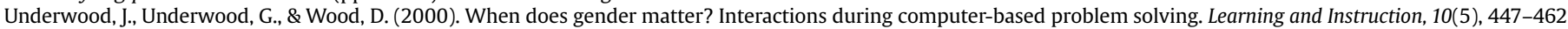

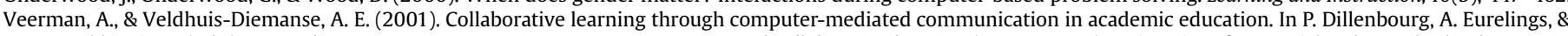
K. Hakkarainen (Eds.), Proceedings European perspectives on computer supported collaborative learning (pp. 625-633). University of Maastricht, the Netherlands.

Warschauer, M. (1997). Computer-mediated collaborative: theory and practice. The Modern Language Journal, 18(4), 470-481.

Weinberger, A., Stegmann, K., \& Fischer, F. (2007). Knowledge convergence in collaborative learning: concepts and assessment. Learning \& Instruction, 17(4), 416-426.

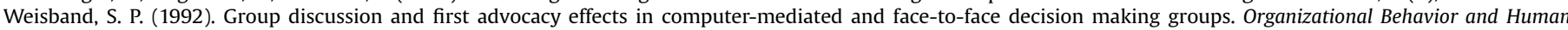
Decision Processes, 53(3), 352-380. 